\title{
General and stereocontrolled approach to the chemical synthesis of naturally occurring cyanogenic glucosides
}

Møller, Birger Lindberg; Olsen, Carl Erik; Motawie, Mohammed Saddik

Published in:

Journal of Natural Products

DOI:

10.1021/acs.jnatprod.5b01121

Publication date:

2016

Document version

Publisher's PDF, also known as Version of record

Citation for published version (APA):

Møller, B. L., Olsen, C. E., \& Motawie, M. S. (2016). General and stereocontrolled approach to the chemical synthesis of naturally occurring cyanogenic glucosides. Journal of Natural Products, 79(4), 1198-1202. https://doi.org/10.1021/acs.jnatprod.5b01121 


\title{
General and Stereocontrolled Approach to the Chemical Synthesis of Naturally Occurring Cyanogenic Glucosides
}

\author{
Birger L. Møller, ${ }^{\dagger, \ddagger \S, \perp}$ Carl E. Olsen, ${ }^{\dagger, \ddagger \S}$ and Mohammed S. Motawia $*^{\dagger, \downarrow, \S}$
}

†Plant Biochemistry Laboratory, Department of Plant and Environmental Sciences, "VILLUM Research Center "Plant Plasticity", and

${ }^{\S}$ Center for Synthetic Biology "bioSYNergy”, University of Copenhagen, 40 Thorvaldsensvej, DK-1871 Frederiksberg C,

Copenhagen, Denmark

${ }^{\perp}$ Carlsberg Laboratory, 10 Gamle Carlsberg Vej, 1799 Copenhagen V, Denmark

\section{Supporting Information}

ABSTRACT: An effective method for the chemical synthesis of cyanogenic glucosides has been developed as demonstrated by the synthesis of dhurrin, taxiphyllin, prunasin, sambunigrin, heterodendrin, and epiheterodendrin. O-Trimethylsilylated cyanohydrins were prepared and subjected directly to glucosylation using a fully acetylated glucopyranosyl fluoride donor with boron trifluoride-diethyl etherate as promoter to afford a chromatographically separable epimeric mixture of the corresponding acetylated cyanogenic glucosides. The isolated epimers were deprotected using a triflic acid/MeOH/ionexchange resin system without any epimerization of the cyanohydrin function. The method is stereocontrolled and provides an efficient approach to chemical synthesis of other naturally occurring cyanogenic glucosides including those with a more complex aglycone structure.

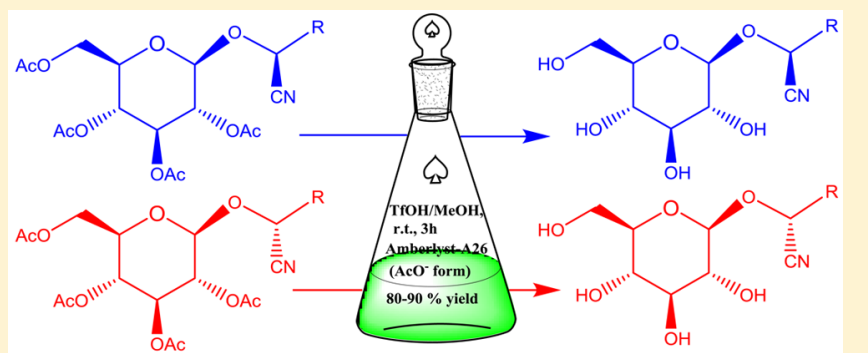

$\mathbf{R}=p-\mathrm{AcO}-\mathrm{C}_{6} \mathrm{H}_{4} ; \mathrm{Ph}$ and $\mathrm{CH}\left(\mathrm{CH}_{3}\right)_{2}$

$\mathbf{R}=p-\mathrm{HO}-\mathrm{C}_{6} \mathrm{H}_{4} ; \mathrm{Ph}$ and $\mathrm{CH}\left(\mathrm{CH}_{3}\right)_{2}$

Completely Stereo-controlled yanogenic glucosides (CGs) are widely distributed in the plant kingdom, and more than 2650 different plant species have been reported to contain cyanogenic glucosides including ferns, gymnosperms, and angiosperms. ${ }^{1}$ Some arthropods, e.g., species within the millipedes and butterflies, are also able to de novo synthesize CGs. ${ }^{2}$ In nature, CGs are derived from only six amino acids, namely, L-valine, Lisoleucine, L-leucine, L-phenylalanine, L-tyrosine, and the nonprotein amino acid cyclopentenylglycine. ${ }^{1}$ Chemically, CGs are defined as $O-\beta$-glycosidic derivatives of $\alpha$-hydroxynitriles (cyanohydrins) as shown in Figure 1. The absolute configuration of the cyanohydrin function may be $R$ or $S$, but a single plant species will contain only a single diastereoisomer.

In the present study, the efficient and fully stereocontrolled chemical synthesis of cyanogenic glycosides is demonstrated. The method is general and exemplified by chemical synthesis of<smiles>[R3]C1CC[C@H](OC([R])([R])C#N)OC1</smiles>

$\mathbf{R}_{1}$ : Mainly $\mathrm{H}$ or $\mathrm{CH}_{3}$

$\mathbf{R}_{2}$ : Structure defined by the side chain of the parent amino acid.

$\mathbf{R}_{3}$ : May be D-Glc $p$ or other types of sugars which may be modified e.g. by acylation.

Figure 1. General chemical structure of cyanogenic glycosides. the CGs dhurrin, prunasin, heterodendrin, and their related epimers taxiphyllin, sambunigrin, and epiheterodendrin, as shown in Figure 2.

The labile cyanohydrin function is stabilized by glycosylation. The sugar moiety directly bound to the cyanohydrin function (e.g., in cyanogenic monoglycosides) is always D-glucose. Other CGs may harbor additional sugar residues including other hexoses as well as pentoses linked in different configurations, giving rise to the large number of different CGs found in nature such as the cyanogenic disaccharides (R)-amygdalin, $(R)$ vicianin, and linustatin and the structurally highly complex cyanogenic trisaccharide xeranthin. ${ }^{1 \mathrm{a}, 3}$

The L-tyrosine-derived cyanogenic glucoside dhurrin $[(S)-4$ hydroxymandelonitrile- $\beta$-D-glucopyranoside] present in sorghum (Sorghum bicolor) has been developed as an experimental model system for studying the biosynthesis and endogenous turnover of cyanogenic glucosides. ${ }^{3 a, 4}$ The biosynthetic pathway is catalyzed by two cytochrome P450s (CYP79A1 and CYP71E1) and the glucosyltransferase UGT85B1 with electron transfer provided by NADPH $\mathrm{P} 450$ oxidoreductase. ${ }^{4,5}$ In synthetic biology approaches, the dhurrin pathway has been used to demonstrate the possibility to transfer entire cytochrome P450-catalyzed pathways into chloroplasts and drive the catalytic cycle of the P450s with direct electron

Received: December 17, 2015

Published: March 9, 2016 
<smiles>N#C[C@H](O[C@@H]1O[C@H](CO)[C@@H](O)[C@H](O)[C@H]1O)c1ccc(O)cc1</smiles>

Dhurrin

$(2 S)$-2-( $\beta$-D-glucopyranosyloxy)4-hydroxyphenylacetonitrile (16)<smiles>N#C[C@@H](O[C@@H]1O[C@H](CO)[C@@H](O)[C@H](O)[C@H]1O)c1ccccc1</smiles>

Sambunigrin

(2S)-2-( $\beta$-D-glucopyranosyloxy) phenylacetonitrile (17)

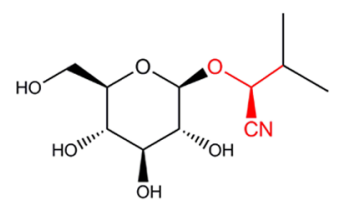

Heterodendrin

(2S)-2-( $\beta$-D-Glucopyranosyloxy)

3-methylbutanenitrile (18)

Figure 2. Structures of the synthetic cyanogenic glucosides: dhurrin, taxiplyllin, prunasin, sambunigrin, heterodendrin, and epiheterodendrin.

transfer from photosystem I without the involvement of NADPH. ${ }^{6}$

Under basic conditions and due to the acidity of the $\alpha-\mathrm{H}$ of CGs, all CGs are susceptible toward basic media and prone to epimerization (isomerization) even in the presence of small amounts of base. ${ }^{7}$ The isomerization proceeds via a carbanion after elimination of the cyanohydrin proton, ${ }^{7 a, 8}$ as shown in Figure 3.

In 1965 , dhurrin was reported to be extremely labile to alkali while showing no special instability toward acids. ${ }^{9}$ The phenolic hydroxy group of dhurrin was proposed as responsible for the observed sensitivity to alkali, and a reaction sequence based on the mechanism for base-catalyzed decomposition of the $p$ - hydroxybenzyl halides and related compounds was proposed ${ }^{10}$ (Figure 4).

These concomitant base sensitivity properties of CGs as well as the inherent instability of their aglycones (cyanohydrins) to hydrolysis have precluded exploration of stereocontrolled chemical synthesis for construction of pure cyanogenic glycosides. Only a few approaches toward chemical synthesis of CGs have been reported. In 1917, chemical synthesis of an epimeric mixture of prunasin and sambunigrin involving a fivestep reaction sequence and an overall yield of less than $2 \%$ was reported. ${ }^{11}$ The only attempt to synthesize dhurrin and taxiphyllin was reported ${ }^{12}$ in 1966 and afforded an epimeric mixture of the pentaacetates of dhurrin and taxiphyllin in 5.9\% yield. No information on how to obtain each of the target molecules by deprotection was provided. Synthesis of heterodendrin was attempted ${ }^{13}$ by Koenigs-Knorr condensation of acetobromoglucose and 2-hydroxy-3-methylbutanenitrile. In spite of numerous variations of the reaction conditions, the yield of the tetraacetates of heterodendrin and its epimer epiheterodendrin was low ( $3 \%$ total yield). Again, no attempts to obtain the target molecules by deprotection were reported. An improved route to chemical synthesis of the cyanogenic glucosides prunasin, linamarin, and heterodendrin has been reported $^{8 \mathrm{~b}}$ in which the final step involved removal of the $\mathrm{O}$ acetyl protecting groups using different basic catalysts $\left(\mathrm{NH}_{3}\right.$, $\mathrm{K}_{2} \mathrm{CO}_{3}$, hydrazine, and $\mathrm{KCN}$ ) in alcoholic medium, which resulted in epimeric mixtures. ${ }^{8 \mathrm{~b}}$

To overcome the base sensitivity issues related to stereocontrolled synthesis of pure cyanogenic glucosides, a novel synthetic approach avoiding any basic treatment has developed. The approach is based on (1) initial stabilization of the aglycone (cyanohydrin) by conversion of its $\mathrm{OH}$ group into an $O$-trimethylsilyl derivative, which at the same time serves to enhance the nucleophilicity of the $\mathrm{OH}$ group, and (2) performing the glucosylation and the deprotection reactions under acidic conditions. On the basis of these principles we succeeded in designing a general and efficient route toward the chemical synthesis of cyanogenic glucosides without epimerization.

Glycosyl fluorides have become important in glycosylation reactions due to their enhanced stability, ease of handling, and high stereoselectivity compared with other glycosyl halides and activation using mild reaction conditions. ${ }^{14}$ The synthesis of

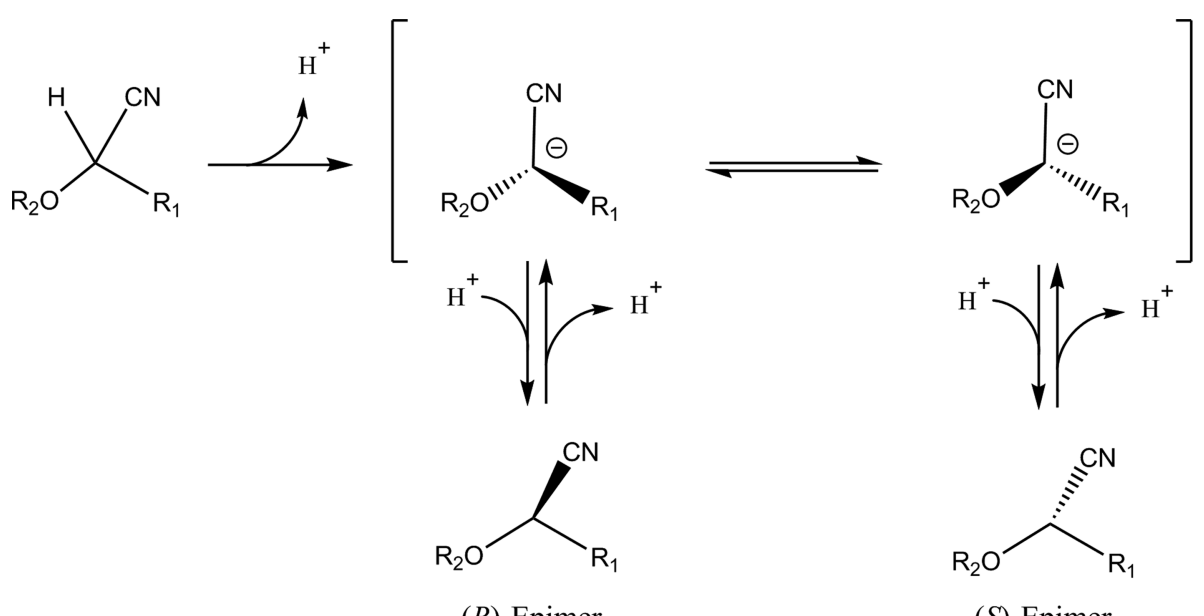

Figure 3. Mechanism for epimerization of cyanogenic glycosides. 


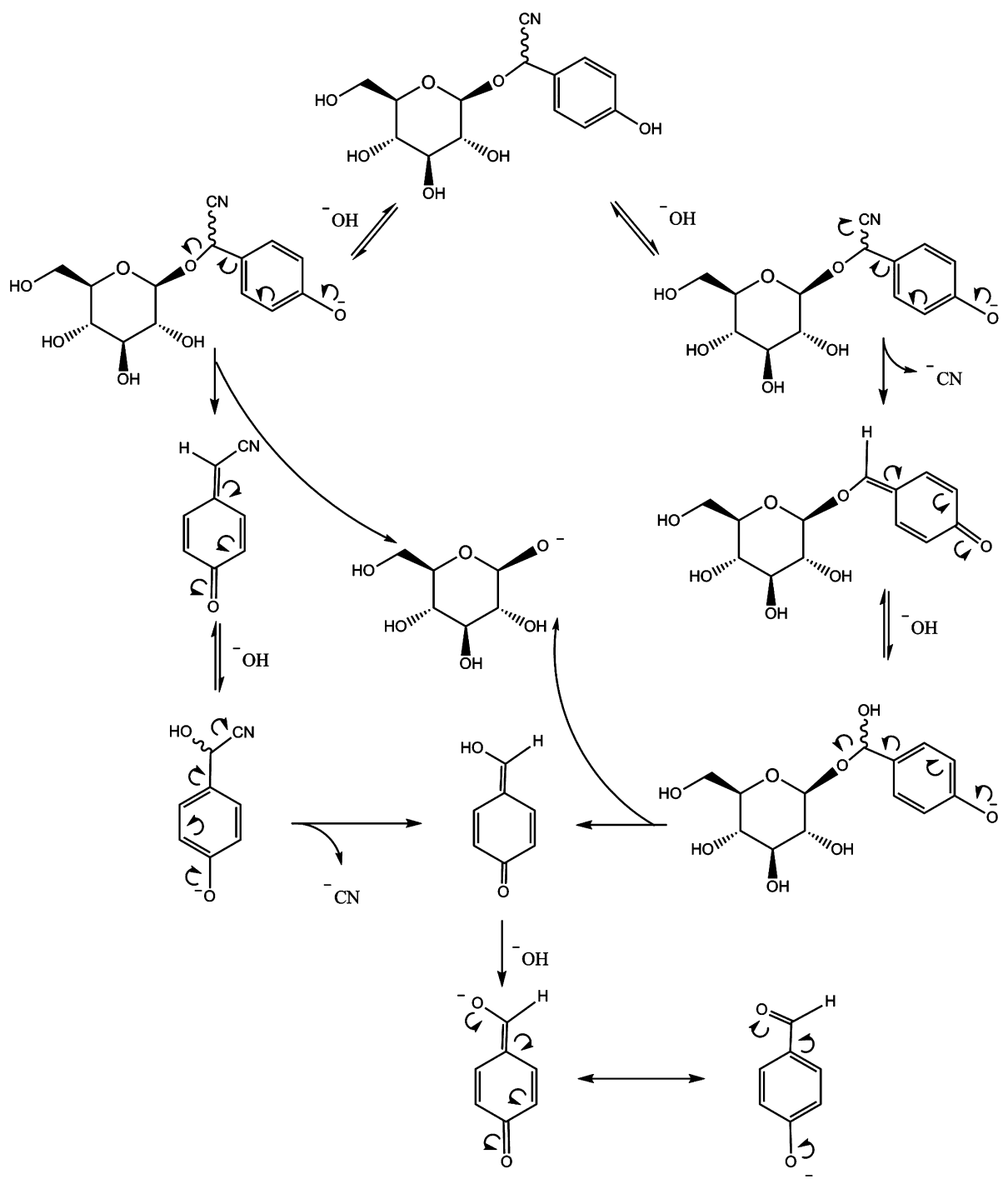

Figure 4. Mechanism of alkaline hydrolysis of dhurrin and/or its epimer taxiphyllin. ${ }^{9}$

glycosyl fluorides can be achieved by various approaches ${ }^{15}$ with diethylaminosulfur trifluoride $(\mathrm{DAST})^{16}$ as the preferred fluorinating reagent of 1-glycoses. Recently, an efficient method for the synthesis of 2,3,4,6-tetra-O-acetyl-D- ${ }^{13} \mathrm{C}_{6} /{ }^{14} \mathrm{C}_{6}$-glucopyranosyl fluoride starting from commercially available $\mathrm{D}$ glucose $-{ }^{13} \mathrm{C}_{6}$ mixed with commercially available D-glucose- ${ }^{14} \mathrm{C}_{6}$ in desired ratios using DAST as the fluorinating agent was reported. ${ }^{17}$ On the basis of this approach, the chemical synthesis of the glucosyl donor 2,3,4,6-tetra-O-acetyl-Dglucopyranosyl fluoride (3) was accomplished starting with the commercially available $1,2,3,4,6$-penta- $O$-acetyl- $\beta$-D-glucopyranose (1) as outlined in Scheme 1.

Compound 1 was deprotected regionselectively at the anomeric position by treatment with a solution of ethylenediamine/HOAc $(1: 1)^{18}$ in THF to obtain 2,3,4,6-tetra-O-acetylD-glucopyranose (2) $(\alpha / \beta=3: 1)$ in $92 \%$ yield. Fluorination of 2 by reaction with DAST in dichloromethane ${ }^{19}$ afforded the glucosyl fluoride 3 as an anomeric mixture $(\alpha / \beta=2: 8)$. The $\alpha$ and $\beta$-anomers were separated by silica gel chromatography $(n-$ pentane $/ \mathrm{Et}_{2} \mathrm{O}, 1: 1 \mathrm{v} / \mathrm{v}$ ) to afford pure $\alpha$ - and $\beta$-anomers of 3 in $93 \%$ overall yield. Both ${ }^{1} \mathrm{H}$ and ${ }^{13} \mathrm{C}$ NMR data were in full agreement with reported data. ${ }^{20}$
Scheme 1. Synthesis of the Glucosyl Donor

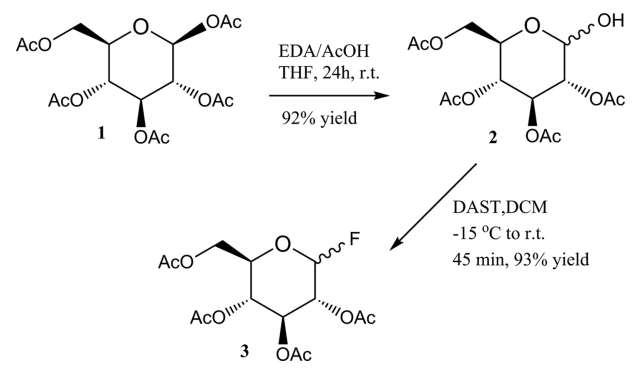

The strategy for the synthesis of a target cyanogenic glucoside is described in Scheme 2.

The commercially available aldehydes 4-O-acetylbenzaldehyde (4), benzaldehyde (5), and isobutyraldehyde (6) were used as starting materials. Aldehydes 4-6 were reacted with trimethysilyl cyanide (TMS-CN) in the presence of $\mathrm{LiClO}_{4}$ under solvent-free conditions ${ }^{21}$ to afford the corresponding $\mathrm{O}$ trimethylsilylated cyanohydrins 7-9 in quantitative yields. Compounds 7-9 were glucosylated by reaction with 3 in the presence of $\mathrm{BF}_{3} \cdot \mathrm{Et}_{2} \mathrm{O}$ as catalyst ${ }^{22}$ in $\mathrm{CH}_{2} \mathrm{Cl}_{2}$ at $\mathrm{rt}$ (Scheme 2) to afford the acetylated cyanogenic glycoside-epimeric mixtures 


\section{Scheme 2. Synthesis of the Cyanogenic Glucosides}

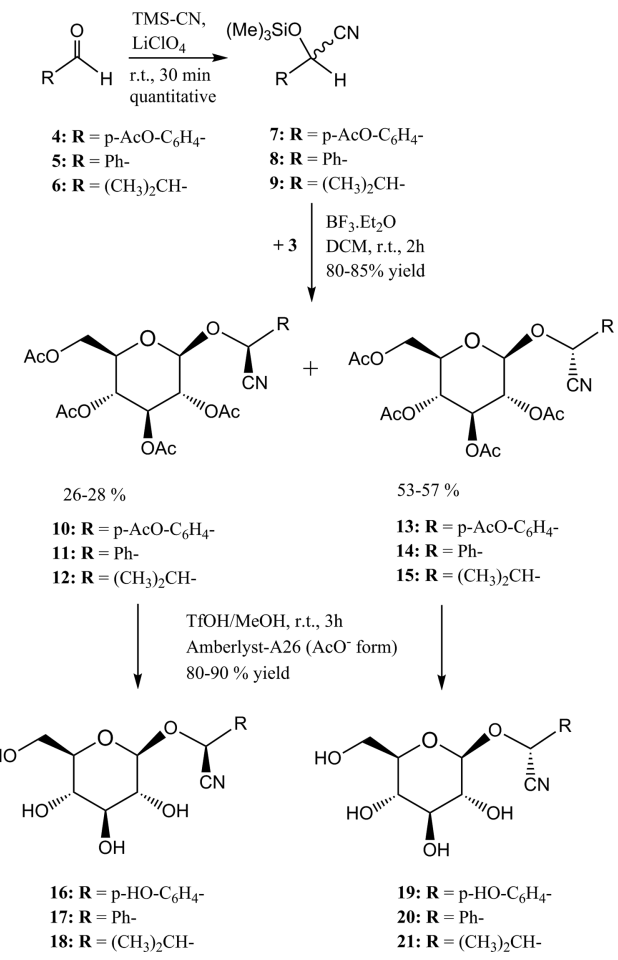

10-12 and $13-15$ in $80-85 \%$ yield. Separation of the $(S)$ epimers 10-12 from the corresponding $(R)$-epimers 13-15 and isolation of the pure stereoisomers were achieved using silica gel chromatography and recrystallization.

Conventionally, removal of $\mathrm{O}$-acetyl groups is performed under base catalysis. Only a few examples of acid-catalyzed removal of $O$-acetyl groups have been reported, ${ }^{23}$ typically using $\mathrm{HCl} / \mathrm{MeOH}$ as standard reagent in connection with a demand for selective removal of $O$-acetyl groups in the presence of $O$-benzoyl groups. ${ }^{23 a-c}$ In all acid-catalyzed reactions, a base is required to neutralize the excess acid at the end of the reaction. This should be avoided in order to prevent epimerization of the synthetic cyanogenic glucosides. When we applied these acid catalysts, only slow and partial deacetylation was observed.

Trifluoromethanesulfonic acid (triflic acid) is one of the strongest Brøndsted-Lowry acids. ${ }^{24}$ Triflic acid and its derivatives constitute a versatile family of useful reagents for organic synthesis. ${ }^{24,25}$ When using it in $\mathrm{MeOH}$ as an acid catalyst for deprotection of compounds 10-15, the removal of the $O$-acetyl groups proceeded smoothly and efficiently within $3 \mathrm{~h}$ at rt. At this time, triflic acid was exchanged with HOAc using an anion ion-exchange resin $\left(\mathrm{HcO}^{-}\right)$(Scheme 2) instead of neutralization using a base as conventionally used. The deprotection step proceeded smoothly without any epimerization and afforded the target molecules $\mathbf{1 6 - 2 1}$ in $80-90 \%$ yield after chromatographic purification on silica gel using $10 \%$ $\mathrm{MeOH}$ in $\mathrm{CH}_{2} \mathrm{Cl}_{2}$ (v/v). The identity and purity of the synthetic compounds were assessed by ESIMS and ${ }^{1} \mathrm{H}$ and ${ }^{13} \mathrm{C}$ NMR data analyses. All NMR spectroscopic data of the synthetic compounds were in full agreement with those reported in the literature (Supporting Information).

\section{EXPERIMENTAL SECTION}

General Experimental Procedures. All reactions were carried out under an atmosphere of argon in oven-dried glassware with magnetic stirring. Unless otherwise indicated, commercially available starting materials, reagents, solvents, and dry solvents were purchased from Sigma-Aldrich Chemicals (Copenhagen, Denmark) and were used without further treatment. All commercial materials were used as received unless otherwise noted. All reactions were monitored by TLC on aluminum sheets coated with silica gel 60F254 (0.2 mm thickness, E. Merck, Darmstadt, Germany) using UV light as a visualizing agent, and the components were detected by charring with $10 \% \mathrm{H}_{2} \mathrm{SO}_{4}$ in $\mathrm{MeOH}$. Column chromatographies were carried out using silica gel 60 (particle size $0.040-0.063 \mathrm{~mm}, 230-400$ mesh ASTM, E. Merck). Solvent extracts were dried over anhydrous $\mathrm{MgSO}_{4}$ unless otherwise specified. The ${ }^{1} \mathrm{H}$ and ${ }^{13} \mathrm{C}$ NMR spectra were recorded on a Bruker Avance 400 spectrometer at 400 and $101 \mathrm{MHz}$, respectively; $\delta$-values are relative to internal TMS; coupling constants $(J)$ are given in $\mathrm{Hz}$. HRESIMS data were recorded on a Bruker micrOTOF-Q mass spectrometer.

Synthesis of 2,3,4,6-Tetra-O-acetyl-D-glucopyranosyl Fluoride, 3 (Scheme 1). Glacial HOAc $(1.2 \mathrm{~mL}, 21 \mathrm{mmol})$ was added dropwise with stirring to a solution of ethylenediamine/HOAc (EDA) $(1.2 \mathrm{~mL}, 18 \mathrm{mmol})$ in THF $(150 \mathrm{~mL})$, resulting in the immediate formation of a precipitate, which remained present until aqueous workup. The peracetate $1(6.0 \mathrm{~g}, 15.4 \mathrm{mmol})$ in THF $(50 \mathrm{~mL})$ was added, and the mixture was stirred at rt for $24 \mathrm{~h}$, after which TLC (silica gel 60 F254 plates Merck, $n$-pentane/acetone, 8:2 v/v) showed complete absence of 1 . Water $(100 \mathrm{~mL})$ was added, and the mixture was extracted with $\mathrm{CH}_{2} \mathrm{Cl}_{2}(3 \times 50 \mathrm{~mL})$. The organic phase was washed sequentially with dilute $\mathrm{HCl}, \mathrm{NaHCO}_{3}(\mathrm{aq})$, and $\mathrm{H}_{2} \mathrm{O}$ and dried. The solvent was evaporated and coevaporated with $96 \% \mathrm{EtOH}$ $(3 \times 50 \mathrm{~mL})$ to obtain a chromatographically pure sample of $2(\alpha / \beta=$ $3: 1,4.9 \mathrm{~g}, 14.1 \mathrm{mmol}, 92 \%$ yield) as a colorless syrup, which was used for the next synthetic step without further purification. Diethylaminosulfur trifluoride $(2.0 \mathrm{~mL}, 15.15 \mathrm{mmol})$ was added to a stirred solution of $2(4.6 \mathrm{~g}, 13.2 \mathrm{mmol})$ in dry $\mathrm{CH}_{2} \mathrm{Cl}_{2}(100 \mathrm{~mL})$ at $-15{ }^{\circ} \mathrm{C}$ under Ar. Stirring was continued, and the temperature allowed to rise to $\mathrm{rt}$ during a $45 \mathrm{~min}$ period. The mixture was diluted with $\mathrm{CH}_{2} \mathrm{Cl}_{2}$ $(50 \mathrm{~mL})$ and filtered through silica gel. The silica gel was washed several times with $\mathrm{CH}_{2} \mathrm{Cl}_{2}(5 \times 25 \mathrm{~mL})$, and the collected filtrate was washed with saturated $\mathrm{NaHCO}_{3}(\mathrm{aq})(2 \times 100 \mathrm{~mL})$, water $(3 \times 100$ $\mathrm{mL})$, and brine $(100 \mathrm{~mL})$ and dried $\left(\mathrm{MgSO}_{4}\right)$. The solvent was evaporated to dryness to obtain a colorless syrup corresponding to glucopyranosyl fluoride 3 as an anomeric mixture. $\alpha$ - and $\beta$-anomers were separated by silica gel chromatography ( $n$-pentane/ether, 1:1 v/ v) to afford pure $\alpha$ - and $\beta$-anomers of 3 ( $4.3 \mathrm{~g}$ in total, $12.3 \mathrm{mmol}$, 93\% yield). (For NMR spectroscopic data see Supporting Information.)

General Procedure for Synthesis of Compounds 10-15 (Scheme 2). A mixture of aldehydes 4-6 $(2.5 \mathrm{mmol})$, solid $\mathrm{LiClO}_{4}$ $(0.27 \mathrm{~g}, 2.5 \mathrm{mmol})$, and TMS-CN $(0.38 \mathrm{~mL}, 3.0 \mathrm{mmol})$ was stirred at rt for $30 \mathrm{~min}$. Then $\mathrm{CH}_{2} \mathrm{Cl}_{2}(30 \mathrm{~mL})$ was added to the mixture, and the $\mathrm{LiClO}_{4}$ was removed by filtration. The organic layer was washed with $\mathrm{H}_{2} \mathrm{O}(15 \mathrm{~mL})$ and dried. The solvent was removed in a rotary evaporator to obtain the corresponding crude $O$-trimethylsilyl cyanohydrins 7-9 (quantitative), which were used directly for the next step. $\mathrm{BF}_{3} \cdot \mathrm{Et}_{2} \mathrm{O}(1.04 \mathrm{~mL}, 8.4 \mathrm{mmol})$ was added in one portion at rt to a stirred solution of the crude $O$-(trimethylsilyl) cyanohydrins 79 and the glucosyl fluoride $3(0.71 \mathrm{~g}, 2 \mathrm{mmol})$ in dry $\mathrm{CH}_{2} \mathrm{Cl}_{2}(30 \mathrm{~mL})$ under Ar. Stirring was continued at $\mathrm{rt}$ for $2 \mathrm{~h}$. The mixture was basified by careful addition of saturated $\mathrm{NaHCO}_{3}(\mathrm{aq})$ and diluted with $\mathrm{CH}_{2} \mathrm{Cl}_{2}$ $(100 \mathrm{~mL})$. The organic phase was washed with $\mathrm{H}_{2} \mathrm{O}(3 \times 5 \mathrm{~mL})$ and brine $(50 \mathrm{~mL})$ and dried, and the $\mathrm{CH}_{2} \mathrm{Cl}_{2}$ evaporated. The residue was purified by chromatography on silica gel to afford compounds 10-15 as stereochemically pure compounds. (For NMR spectroscopic data see Supporting Information.)

Preparation of Amberlyst $\mathrm{A} 26\left(\mathrm{CH}_{3} \mathrm{COO}^{-}\right.$Form). Amberlyst A26 hydroxide form (commercially available from Sigma-Aldrich, 542571 Aldrich) was added to an excess of $1 \mathrm{~N} \mathrm{HOAc(aq)} \mathrm{and}$ magnetically stirred for $1 \mathrm{~h}$ at room temperature. The resin was filtered 
off and washed with deionized $\mathrm{H}_{2} \mathrm{O}$ until the $\mathrm{pH}$ was neutral, then washed with acetone $(3 \times 100 \mathrm{~mL})$ and $\mathrm{MeOH}(3 \times 100 \mathrm{~mL})$, airdried, and used as such. The used resin can be readily regenerated with $1 \mathrm{~N} \mathrm{NaOH}$ to its hydroxide form and reused.

General Procedure for Synthesis of Compounds 16-21 (Scheme 2). Trifluoromethanesulfonic acid (triflic acid: TfOH) (0.65 $\mathrm{mL}, 7.34 \mathrm{mmol}$ ) was added in one portion at $\mathrm{rt}$ to a stirred solution of 10-15 $(1.18 \mathrm{mmol})$ in dry $\mathrm{MeOH}(5 \mathrm{~mL})$ under Ar. Stirring was continued at $\mathrm{rt}$ for $3 \mathrm{~h}$, and the reaction mixture was diluted with $\mathrm{MeOH}(25 \mathrm{~mL})$, neutralized with Amberlyst-A26 $\left(\mathrm{CH}_{3} \mathrm{COO}^{-}\right.$form $)$ resin, filtered, and evaporated to dryness. The residue was chromatographed on silica gel with $10 \% \mathrm{MeOH} / \mathrm{CH}_{2} \mathrm{Cl}_{2}$ as eluent to afford compounds 16-21 in $80-85 \%$ yield. (For NMR spectroscopic data see the Supporting Information).

In conclusion, we have developed an effective method for the chemical synthesis of dhurrin, prunasin, heterodendrin, and their related epimers taxiphyllin, sambunigrin, and epiheterodendrin. The method is stereocontrolled and provides an efficient approach to the chemical synthesis of other cyanogenic glycosides including those that have more complex glycone structures. The method also provides for the synthesis of cyanogenic glucosides where the glycone is labeled with radioactive or stable isotopes. ${ }^{17}$ In general, the synthetic strategy offers unique insights into the synthesis of base-sensitive glucosides. The availability of synthetic pure cyanogenic glucosides will advance biochemical studies on the yet uncharacterized enzymes involved in endogenous turnover of cyanogenic glucosides in plants and their role as storage compounds of reduced nitrogen. ${ }^{3 a}$ Studies on sequestering, metabolism, and excretion of cyanogenic glucosides in insects feeding on cyanogenic plants will also benefit especially from access to isotopically labeled cyanogenic glucosides. ${ }^{17,26}$

\section{ASSOCIATED CONTENT}

\section{S Supporting Information}

The Supporting Information is available free of charge on the ACS Publications website at DOI: 10.1021/acs.jnatprod.5b01121.

Experimental procedures and ${ }^{1} \mathrm{H}$ and ${ }^{13} \mathrm{C}$ NMR spectroscopic data; copies of ${ }^{1} \mathrm{H}$ and ${ }^{13} \mathrm{C}$ NMR spectra of all synthesized compounds 2-21 (PDF)

\section{AUTHOR INFORMATION}

\section{Corresponding Author}

*E-mail: mosm@plen.ku.dk (M. S. Motawia). Phone: (+45) 35333305 .

\section{Notes}

The authors declare no competing financial interest.

\section{ACKNOWLEDGMENTS}

This work was supported by the VILLUM Research Center "Plant Plasticity" and by the Center for Synthetic Biology "bioSYNergy" supported by the UCPH Excellence Program for Interdisciplinary Research.

\section{REFERENCES}

(1) (a) Møller, B. L. Curr. Opin. Plant Biol. 2010, 13, 338-347. (b) Gleadow, R. M.; Møller, B. L. Annu. Rev. Plant Biol. 2014, 65, 155-185.

(2) Larsen, M. Z.; Møller, B. L. Phytochemistry 2011, 72, 1585-1592. (3) (a) Picmanova, M.; Neilson, E. H.; Motawia, M. S.; Olsen, C. E.; Agerbirk, A.; Gray, C. J.; Flitsch, S.; Silvestro, D.; Jørgensen, K.; Sanchez-Perez, R.; Møller, B. L.; Bjarnholt, N. Biochem. J. 2015, 469, 375-389. (b) Neilson, E. H.; Goodger, J. Q. D.; Motawia, M. S.; Bjarnholt, N.; Frisch, T.; Olsen, C. E.; Møller, B. L.; Woodrow, J. E. Phytochemistry 2011, 72, 2325-2334. (c) Schwind, P.; Nahrstedt, A.; Wray, V. Planta Med. 1989, 55, 600.
(4) Tattersall, D. B.; Bak, S.; Jones, P. R.; Olsen, C. E.; Nielsen, J. K.; Hansen, M. L.; Høj, P. B.; Møller, B. L. Science 2001, 293, 1826-1828. (5) (a) Kahn, R. A.; Bak, S.; Svendsen, I.; Halkier, B. H.; Møller, B. L. Plant Physiol. 1997, 115, 1661-1670. (b) Busk, P. K; Møller, B. L. Plant Physiol. 2002, 129, 1222-1231. (c) Sibbesen, O.; Koch, B.; Møller, B. L. J. Biol. Chem. 1995, 270, 3506-3511. (d) Nielsen, K. A.; Tattersall, D. B.; Jones, P. R.; Møller, B. L. Phytochemistry 2008, 69, 88-98. (e) Bak, S.; Olsen, C. E.; Halkier, B. A.; Møller, B. L. Plant Physiol. 2000, 123, 1437-1448.

(6) (a) Møller, B. L. The Royal Society of Chemistry, Specialist Periodical Reports. Synthetic Biology; Ryadnov, M.; Brunsveld, L.; Suga, H., Eds.; 2014; Vol. 1, pp 330-359. (b) Lassen, L. M.; Nielsen, A. Z.; Ziersen, B.; Gnanasekaran, T.; Møller, B. L.; Jensen, P. E. ACS Synth. Biol. 2014, 3, 1-12.

(7) (a) Nahrstedt, A. Arch. Pharm. 1975, 308, 903-910. (b) Ettlinger, M.; Jaroszewski, J. W.; Jenson, S. R.; Nielsen, B. J.; Nartey, F. J. J. Chem. Soc., Chem. Commun. 1977, 952-953.

(8) (a) Turczan, J. W.; Medwick, T. H. Ass. Off. Anal. Chem. 1979, 62, 190-196. (b) Nakajima, N.; Ubukata, M. Biosci., Biotechnol., Biochem. 1998, 62, 453-458. (c) Sendker, J.; Nahrstedt, A. Phytochem. Anal. 2010, 21, 575-581.

(9) Mao, C.-H.; Anderson, L. J. Org. Chem. 1965, 30, 603-607.

(10) Filar, L. J.; Winatein, S. Tetrahedron Lett. 1960, 25, 9-16.

(11) Fischer, E.; Bergman, M. Ber. Dtsch. Chem. Ges. 1917, 50, 10471069.

(12) Kofod, H.; Eyjolfss, R. Tetrahedron Lett. 1966, 5249-5251.

(13) Jaroszewski, J. W. J. Nat. Prod. 1986, 49, 927-928.

(14) Toshima, K. Carbohydr. Res. 2000, 327, 15-26.

(15) Shimizu, M.; Togo, H.; Yokoyama, M. Synthesis 1998, 1998, 799-822.

(16) (a) Posner, G. H.; Haines, S. R. Tetrahedron Lett. 1985, 26, 5-8. (b) Rosenbrook, W.; Riley, D. A.; Lartey, P. A. Tetrahedron Lett. 1985, 26, 3-4.

(17) Zagrobelny, M.; Olsen, C. E.; Pentzold, S.; Furstenberg-Hagg, J.; Jørgensen, K.; Bak, S.; Møller, B. L.; Motawia, M. S. Insect Biochem. Mol. Biol. 2014, 44, 44-53.

(18) Zhang, J.; Kovacs, P. J. Carbohydr. Chem. 1999, 18, 461-469.

(19) Middleton, W. J. J. Org. Chem. 1975, 40, 574-578.

(20) Griffith, M. H. E.; Hindsgaul, O. Carbohydr. Res. 1991, 211, $163-166$.

(21) Azizi, N.; Saidi, M. R. J. Organomet. Chem. 2003, 688, 283-285.

(22) Kunz, H.; Sager, W. Helv. Chim. Acta 1985, 68, 283-287.

(23) (a) Corey, E. J.; Clark, D. A.; Goto, G.; Marfat, A.; mioskowsli, C.; Samuelsson, B.; Hmmarstron, C. J. Am. Chem. Soc. 1980, 102, 1436-1439. (b) Byramova, N. E.; Ovchinnikov, M. V.; Backinowsky, L. V.; Kochetkov, N. K. Carbohydr. Res. 1983, 124, C8-C11. (c) Petrakova, E.; Schraml. Collect. Czech. Chem. Commun. 1983, 48, 877-888. (d) Askin, D.; Angst, C.; Danishefsky, S. J. Org. Chem. 1987, 52, 622-635. (e) Pozsgay, V.; Coxon, B. Carbohydr. Res. 1993, 257, 189-215.

(24) Howells, R. D.; McCown, J. D. Chem. Rev. 1977, 77, 69-92.

(25) (a) Rakita, P. E. Chem. Today 2004, 48-50. (b) Sbramanian, L. R; Martinez, A. G.; Hanack, M.; Prakash, G. K. S.; Hu, J. Encyclopedia of Reagents for Organic Synthesis: Trifluoromethanesulfonic Acid; John Wiley \& Sons: New York, 2006.

(26) Pentzold, S.; Zagrobelny, M.; Khakimov, B.; Engelsen, S. B.; Cluasen, H.; Petersen, B. L.; Borch, J.; Møller, B. L.; Bak, S. Sci. Rep. 2015, in press. 